\title{
Novel pathway of cypermethrin biodegradation in a Bacillus sp. strain SG2 isolated from cypermethrin-contaminated agriculture field
}

\author{
Pankaj $^{1}\left(\mathbb{D} \cdot\right.$ Anita Sharma $^{1} \cdot$ Saurabh Gangola ${ }^{1} \cdot$ \\ Priyanka Khati $^{1}$ - Govind Kumar ${ }^{1}$ Anjana Srivastava ${ }^{2}$
}

Received: 21 August 2015/Accepted: 14 September 2015/Published online: 4 February 2016

(c) The Author(s) 2016. This article is published with open access at Springerlink.com

\begin{abstract}
Pesticides belonging to pyrethroid group are widely used in agricultural fields to check pest infestation in different crops for enhanced food production. In spite of beneficial effects, non-judicious use of pesticides imposes harmful effect on human health as their residues reach different food materials and ground water via leaching, percolation and bioaccumulation. Looking into the potential of microbial degradation of toxic compounds under natural environment, a cypermethrin-degrading Bacillus sp. was isolated from pesticide-contaminated soil of a rice field of Distt. Udham Singh Nagar, Uttarakhand, India. The bacteria degraded the compound up to $81.6 \%$ within 15 days under standard growth conditions (temperature $32{ }^{\circ} \mathrm{C} \mathrm{pH} 7$ and shaking at $116 \mathrm{rpm}$ ) in minimal medium. Analysis of intermediate compounds of biodegraded cypermethrin revealed that the bacteria opted a new pathway for cypermethrin degradation. GC-MS analysis of biodegraded cypermethrin showed the presence of 4-propylbenzoate, 4-propylbenzaldehyde, phenol M-tertbutyl and 1-dodecanol, etc. which was not reported earlier in cypermethrin metabolism; hence a novel biodegradation
\end{abstract}

Electronic supplementary material The online version of this article (doi:10.1007/s13205-016-0372-3) contains supplementary material, which is available to authorized users.

Pankaj

pankajbhatt.bhatt472@gmail.com

1 Department of Microbiology, College of Basic Sciences and Humanities, G.B Pant University of Agriculture and Technology, Pantnagar 263145, India

2 Department of Chemistry, College of Basic Sciences and Humanities, G.B Pant University of Agriculture and Technology, Pantnagar 263145, India pathway of cypermethrin with Bacillus sp. strain SG2 is proposed in this study.

Keywords Bacillus sp. · Biodegradation - Cypermethrin · GC-MS · Pyrethroid

\section{Introduction}

Pyrethroid insecticides are synthetic derivatives of compounds of pyrethrin, produced by Chrysanthemum plants (Soderlund et al. 2002). These pesticides are widely used in agriculture, forestry, horticulture, public health and homes as well as for the protection of textiles and buildings (Lin et al. 2011; Zhang et al. 2011). In agriculture, these pesticides are being used for more than 40 years (Narahashi et al. 1998; Shafer et al. 2005). Extensive use of these insecticides not only results in pest resistance but also leads to several environmental issues including human health ( $\mathrm{Li}$ et al. 2008). Cypermethrin is mainly used in cereal and ornamental plants against coleopteran (Tribolium confusum), lepidepteran and other broad group of insect larva. This pesticide is also toxic for fish. Freshwater fish (Channa punctatus) exposed to cypermethrin show reduced resistance because of low levels of red blood cells and proteins in the blood (Saxena and Saxena 2010). High levels of this chemical are neurotoxic and cause ataxia, excessive salivation, choreoatheosis, tremors and convulsions in rabbits (Khanna et al. 2002). Cypermethrin affects the voltage-dependent sodium channel and ATPase system in neuronal membranes. It binds to nuclear DNA and leads to destabilization and unwinding of DNA (Patel et al. 2006).

Looking into the facts of toxicity and persistency of this pesticide, it is urgently required to develop some strategies 
to eliminate or detoxify cypermethrin and its metabolites from the environment. Microbial diversity is the major factor in determining the fate of numerous xenobiotic/recalcitrant compounds in a contaminated environment. Biodegradation process involves the use of living microorganisms to detoxify or degrade the pollutants to less toxic forms. Till date, several bacterial strains such as Pseudomonas aeruginosa (Zhang et al. 2011), Streptomyces sp. (Lin et al. 2011), Stenotrophomonas sp. (Chen et al. 2011a) and Serratia marcescens (Cycoń et al. 2014a, b) have been reported to degrade pyrethroid pesticides. Many enzymes involved in biodegradation of cypermethrin and other pyrethroids are reported by Zhai et al. (2012) and Fan et al. (2012).In the present study, a Bacillus sp. (SG2) able to degrade cypermethrin was recovered from the pesticide-contaminated soil of a rice field of Tarai region of Uttarakhand. Biodegradation products of cypermethrin were analysed and possible biodegradation pathway of cypermethrin by Bacillus sp. (SG2) is proposed.

\section{Materials and methods}

\section{Chemicals and media}

Technical grade cypermethrin (95\% pure) was obtained from Department of Chemistry of the University and dissolved in acetonitrile to make a stock of $1 \mathrm{mg} / \mathrm{ml}$. Stock solution was filter sterilized and kept in refrigerator for use. Minimal salt medium and nutrient broth $(\mathrm{pH}$ 7.0) were used for the isolation and cultivation of pesticide-degrading bacterial strains according to Negi et al. (2014). All the chemicals and solvents used in this study were of analytical grade.

\section{Screening and isolation of cypermethrin-degrading bacteria}

Pesticide-contaminated soils were collected from a rice field of Udham Singh Nagar, Uttarakhand, India. As per the result of residual analysis of the pesticide, the soil samples were used for the isolation of cypermethrin-degrading bacteria. One gramme soil was suspended in sterile distilled water. After dilution, one $\mathrm{ml}$ of soil suspension $\left(10^{-5}\right)$ was inoculated in nutrient agar plates. Bacterial colonies that appeared after $24 \mathrm{~h}$ on nutrient agar were enriched with cypermethrin by growing them successively in minimal medium. Discrete and pure bacterial colonies were transferred to $50 \mathrm{ml}$ nutrient broth and incubated at $30{ }^{\circ} \mathrm{C}$ on an incubator shaker at $100 \mathrm{rpm}$. Cypermethrindegrading bacterial cultures were screened from the isolated pure bacterial cultures by growing them in minimum salt agar plates supplemented with $50 \mathrm{ppm}$ cypermethrin as described by Xu et al. (2008) and Negi et al. (2014). Selected bacteria (SG2) utilized cypermethrin as a carbon and energy source. Biodegradation studies of cypermethrin were monitored by analysing residual cypermethrin and its intermediates (after extraction) using a high-performance liquid chromatography system (HPLC-Dionex) at Department of Chemistry.

\section{Identification of cypermethrin degrading bacterial strain}

Microbiological and biochemical characterization of the cypermethrin-degrading bacterial strain (SG2) was performed according to Holt et al. (1994). For molecular characterization, genomic DNA of SG2 was extracted according to Bazzicalupo and Fani (1995). Amplification of $16 \mathrm{~S}$ rDNA was done using Universal primers, $5^{\prime}$ AGAGTTTGATCCTGGCTCAG- $3^{\prime}$ and $5^{\prime}$-TACCTTGTTACGACTT $-3^{\prime}$. PCR conditions used for the present study were initial denaturation at $95^{\circ} \mathrm{C}$ for $1 \mathrm{~min}$, annealing temperature $55-51{ }^{\circ} \mathrm{C}$ (touchdown) followed by 35 cycles of denaturation at $94{ }^{\circ} \mathrm{C}$ for $30 \mathrm{~s}$, annealing at $51{ }^{\circ} \mathrm{C}$ for $30 \mathrm{~s}$ and extension at $72{ }^{\circ} \mathrm{C}$ for $1 \mathrm{~min}$, with the last cycle followed by $10 \mathrm{~min}$ extension at $72{ }^{\circ} \mathrm{C}$. After gel electrophoresis, PCR product was eluted using an extraction kit (Genei). After quantification, the sample was sent to Advanced Biotechnology Centre (CIF), Delhi University South Campus, India, for sequencing. Obtained sequences were compared with GenBank database using BLAST programme. Multiple sequence alignment for the homologous sequence was done by MEGA 5.0 software, and a phylogenetic tree was constructed using neighbour-joining method (Tamura et al. 2007).

\section{Growth-linked biodegradation of cypermethrin in SG2}

In vitro biodegradation of cypermethrin was performed in $100 \mathrm{ml}$ flask with $50 \mathrm{ml}$ minimal salt medium, supplemented with $50 \mathrm{ppm}$ cypermethrin and inoculated with $1 \mathrm{ml} \mathrm{SG} 2$ culture before optimization the biodegradation conditions. Bacterial inoculum was prepared by inoculating single colony in $50 \mathrm{ml}$ of MSM. Inoculated flask was incubated in an incubator shaker @ $100 \mathrm{rpm}$ at $30{ }^{\circ} \mathrm{C}$. Bacterial cells from the $\log$ phase, harvested by centrifugation (5000 rpm for $10 \mathrm{~min}$ ) and washed with minimal medium were used for the subsequent studies. Uninoculated medium acted as control. Bacterial growth was monitored by taking absorbance using UV-Visible spectrophotometer (Perkin Elmer) and the residual cypermethrin concentration was measured by HPLC (Dionex), after extraction according to Anastassiades et al. (2003). 


\section{Optimization of culture conditions for cypermethrin biodegradation}

Response surface methodology (RSM) was explored to optimize the degradation conditions of cypermethrin using strain SG2. The Box-Behnken design with three replicates at the centre point was used to optimize the independent variables which significantly influenced cypermethrin biodegradation with Bacillus sp. according to Xiao et al. (2015). Three critical factors and their optimal ranges selected for biodegradation of cypermethrin in this experiment were temperature $\left(28-38{ }^{\circ} \mathrm{C}\right), \mathrm{pH}(4-8)$ and shaking (90-110 rpm) (Table 1). The dependent variable was degradation of $50 \mathrm{ppm}$ cypermethrin in $50 \mathrm{ml}$ of minimal medium at 15 th day.

\section{FT-IR analysis of cypermethrin biodegradation}

An in vitro pesticide biodegradation study was conducted in $50 \mathrm{ml}$ minimal salt medium, inoculated with1 $\mathrm{ml}$ of 24-h-old bacterial culture and supplemented with cypermethrin $(50 \mathrm{ppm})$. Uninoculated flasks spiked with same concentration of cypermethrin acted as control. Experiment was conducted in triplicate. Intermediate compounds of

Table 1 Box-Behnken design and the response of dependent variable in cypermethrin biodegradation

\begin{tabular}{llcll}
\hline Run & X1 & X2 & X3 & $\begin{array}{l}\text { Percent degradation } \\
\text { by SG2 }\end{array}$ \\
\hline 1 & 28 & 5 & 90 & 71.4 \\
2 & 36 & 5 & 90 & 65.6 \\
3 & 28 & 9 & 90 & 77 \\
4 & 36 & 9 & 90 & 74.5 \\
5 & 28 & 5 & 110 & 65.7 \\
6 & 36 & 5 & 110 & 67.9 \\
7 & 28 & 9 & 110 & 74 \\
8 & 36 & 9 & 110 & 69.7 \\
9 & 25.2 & 7 & 100 & 69.8 \\
10 & 38.7 & 7 & 100 & 68.9 \\
11 & 32 & 3.6 & 100 & 64.8 \\
12 & 32 & 10.3 & 100 & 61.2 \\
13 & 32 & 7 & 83.1 & 76.5 \\
14 & 32 & 7 & 116.8 & 81.6 \\
15 & 32 & 7 & 100 & 80 \\
16 & 32 & 7 & 100 & 74.7 \\
17 & 32 & 7 & 100 & 74 \\
18 & 32 & 7 & 100 & 73 \\
19 & 32 & 7 & 100 & 72 \\
20 & 32 & 7 & 100 & 77 \\
\hline
\end{tabular}

The data are means of three replicates

$X 1$ temperature, $\left(25,28,32,36\right.$ and $\left.38^{\circ} \mathrm{C}\right) ; X 2$ medium $\mathrm{pH},(3.6,5,7$, $9,10) ; X 3$ Shaking speed in rpm, $(83.1,90,100,110,116.8)$ cypermethrin were extracted in acetonitrile after 15 days according to Negi et al. (2014). Samples were analysed by FT-IR at Department of Biophysics to locate the bond stretching in the test pesticide after biodegradation.

\section{GC-MS analysis of cypermethrin biodegradation}

To check the degradation of cypermethrin in soil slurry, $50 \mathrm{~g}$ autoclaved soil was taken in a 100-ml flask, to which $20 \mathrm{ml}$ of minimal medium was added. Cypermethrin (100 ppm) was added to all the sets, to which $1 \mathrm{ml}$ of 24-hold bacterial culture was added and mixed properly. One $\mathrm{ml}$ of soil slurry was taken from all the flasks separately on 0,10 and 15 th day after incubation. Uninoculated flasks spiked with pesticides acted as control. Extraction and quantification of cypermethrin was done by HPLC. For GC-MS analysis, samples were extracted from soil slurry and metabolites of biodegraded cypermethrin were identified at AIRF facility, JNU, New Delhi.

\section{Chemical analysis}

Residual analysis of cypermethrin in collected soil samples was performed according to Anastassiades et al. (2003). Residual pesticide was extracted by adding either $5 \mathrm{ml}$ of culture broth or $5 \mathrm{~g}$ of soil to $20 \mathrm{ml}$ of acetone in a flask. The mixture was filtered using Buchner funnel after shaking for $1 \mathrm{~h}$ and the obtained residue was filtered again after washing thoroughly with $10 \mathrm{ml}$ acetone. Filtrate was collected in a round-bottom flask. The residual analysis of the pesticide was done using HPLC attached with C18 reverse-phase column and UV detector. A mixture of acetonitrile and water $(70: 30, \mathrm{v} / \mathrm{v})$ was used as a mobile phase at a flow rate of $1.0 \mathrm{~mL} \mathrm{~min}{ }^{-1}$ with the injection volume of $10 \mu \mathrm{L}$.

\section{Results \\ Isolation and characterization of cypermethrin- degrading bacteria}

In the present study, a bacterial isolate (SG2), able to utilize cypermethrin as a carbon source, was isolated from the pesticide-contaminated soil of a rice field of Udham Singh Nagar Uttarakhand, India. Bacterial colonies, growing on nutrient agar plates, were rough, opaque and dirty white.The organism was aerobic, gram-positive, rod-shaped and showed positive tests for the production of Indole -3 acetic acid and siderophore and phosphate solubilisation. The bacteria utilized dextrose and mannitol as carbon source and degraded $80 \%$ of cypermethrin (50 ppm) within 


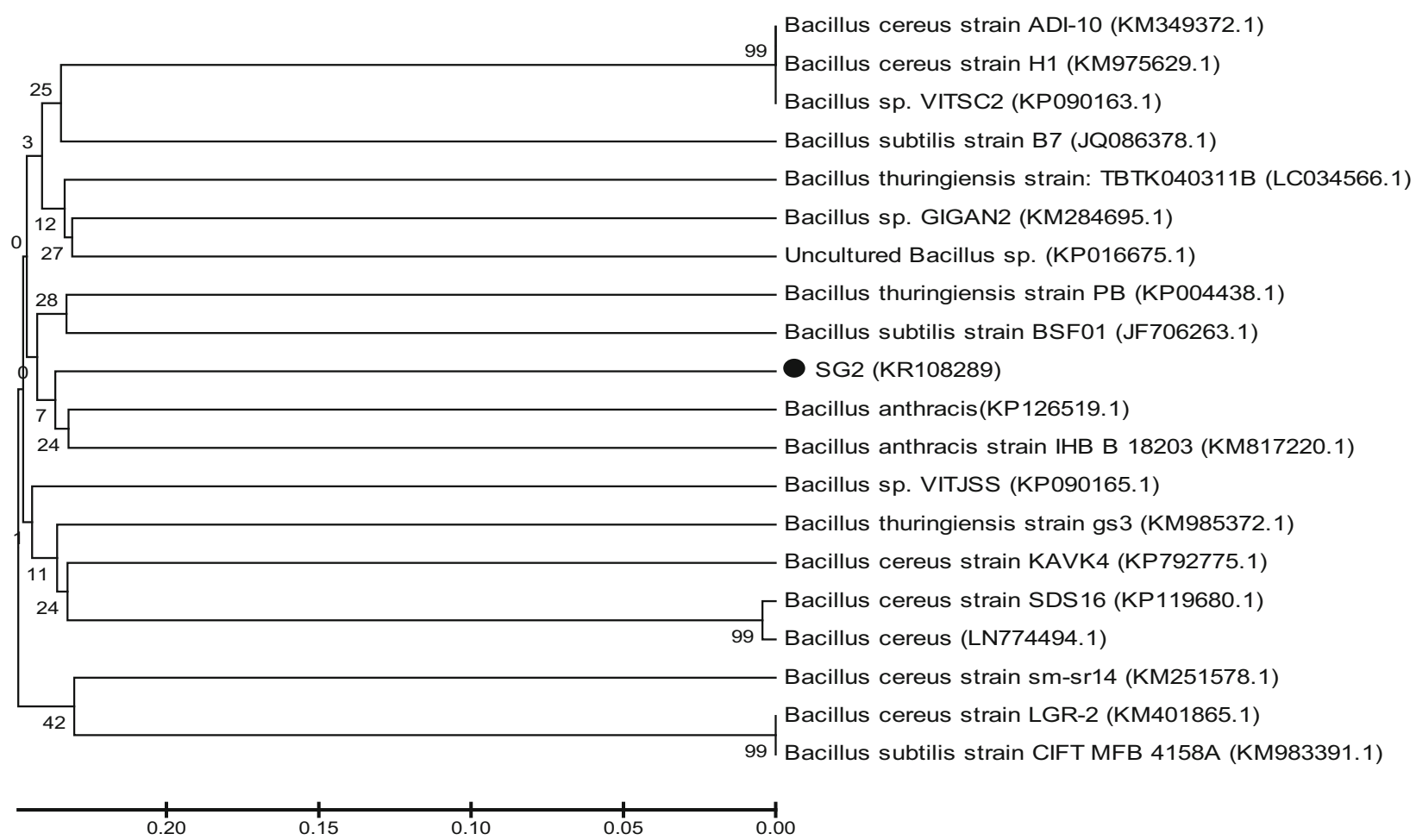

Fig. 1 Phylogenetic analysis of SG2 strain and related strains on the basis of 16S rDNA using MEGA 5.0 software. The numbers in parentheses represent the sequence accession number in Genbank. Bar represents sequence divergence

15 days under shaking conditions in minimal medium. Analysis of the 16S rDNA gene sequences demonstrated that SG2 belonged to Bacillus sp. The organism was provided an accession number (KR108289) by NCBI data base (Fig. 1).

\section{Utilization of cypermethrin by strain SG2}

The isolate, Bacillus sp. (SG2), was able to grow on MSM agar plates supplemented with 110-170 ppm cypermethrin. Degradation rate of cypermethrin increased gradually as the strain entered the logarithmic phase (4-5 days) followed by stationary phase (7-8 days) (Fig. 2). A decline in degradation rate was observed when the strain attained the death phase (12 days). More than $81 \%$ of cypermethrin (50 ppm) was degraded by strain SG2 within 15 days in comparison to control.

\section{Optimization of cypermethrin degradation}

Box-Behnken design was used to determine the effect of three important variables [temperature $(X 1), \mathrm{pH}(X 2)$ and shaking speed (X3)] on the biodegradation of cypermethrin by Bacillus sp. (SG2). The experimental design and the response of dependent variables for cypermethrin are presented in Table 1. Data from Table 1 were processed by response surface regression procedure of Design Expert 6.0.10 software, and results were obtained by fitting the values in the quadratic model equation:

$$
\begin{aligned}
\text { Response }(Y)= & +80.21-0.63 X 1+0.85 X 2+0.32 X 3 \\
& -3.53 X 1^{2}-6.17 X 2^{2}-0.49 X 3^{2} \\
& +0.47 X 1 X 2-0.10 X 1 X 3+0.32 X 2 X 3
\end{aligned}
$$

where $(Y)$ is the predicted cypermethrin degradation (\%) by strain SG2 and $X 1, X 2$ and $X 3$ are the values for temperature, $\mathrm{pH}$ and shaking speed, respectively. Analysis of variance (ANOVA) for cypermethrin degradation is presented in Table 2. Determination coefficient $R^{2}=0.8863$ indicated that approximately $88 \%$ of responses were covered by the model, demonstrating that predicted values of the model were in good agreement with the experimental values. The model for cypermethrin biodegradation is highly significant $(p<0.0001)$, indicating that the established quadratic model for cypermethrin degradation by SG2 was adequate and reliable and represented actual relationship between response and variables (Fig. 3).

\section{FT-IR analysis of biodegraded cypermethrin}

Degradation of cypermethrin in soil slurry was maximum as compared to minimal broth (data not shown). Cypermethrin degradation in mimimal media and in soil slurry 
Fig. 2 Utilization of cypermethrin by strain SG2 (filled circle) growth of SG2, (filled square) utilization kinetics of cypermethrin, (filled triangle) Control



Table 2 ANOVA for the fitted quadratic model for cypermethrin biodegradation

\begin{tabular}{llrllr}
\hline Source & SS & DF & MS & F value & $P$ level \\
\hline Model & 694.1558 & 9 & 77.12842 & 8.656952 & 0.0012 \\
X1 & 5.432684 & 1 & 5.432684 & 0.609769 & 0.4530 \\
X2 & 9.760639 & 1 & 9.760639 & 1.095541 & 0.3199 \\
X3 & 1.402913 & 1 & 1.402913 & 0.157464 & 0.6998 \\
X1X1 & 180.0615 & 1 & 180.0615 & 20.21024 & 0.0012 \\
X2X2 & 548.3952 & 1 & 548.3952 & 61.55229 & $<0.0001$ \\
X3X3 & 3.519622 & 1 & 3.519622 & 0.395045 & 0.5437 \\
X1X2 & 1.805 & 1 & 1.805 & 0.202595 & 0.6622 \\
X1X3 & 0.08 & 1 & 0.08 & 0.008979 & 0.9264 \\
X2X3 & 0.845 & 1 & 0.845 & 0.094843 & 0.7644 \\
Residual & 89.0942 & 10 & 8.90942 & & \\
Lack of fit & 85.8942 & 5 & 17.17884 & 26.84194 & 0.0013 \\
Pure error & 3.2 & 5 & 0.64 & & \\
Cor total & 783.25 & 19 & & & \\
\hline
\end{tabular}

$R^{2}=0.8863, \mathrm{CV}=4.07$

$D F$ degrees of freedom, $S S$ sum of sequences, $M S$ mean square

* $P$ level $<0.05$ indicates that the model terms are significant

was 81.6 and $89 \%$, respectively, after 15 days with SG2. FTIR studies were conducted to identify the changes in bonding/streching and vibrations in biodegraded cypermethrin. Five major peaks were present at 1376, 1458, $2857.7,2924.9,2958.6 \mathrm{~cm}^{-1}$ in control. Significant changes in peak pattern of cypermethrin under bacterial treatment as compared to control were observed (Fig. 4a, b). Absorbance of the bands, associated with ether-cyanate and ester group was 1376 and $1100 \mathrm{~cm}^{-1}$, respectively. A decrease in cypermethrin carbonyl band $\left(1740 \mathrm{~cm}^{-1}\right)$ and a slight increase in carbonyl signals (around 1650-1700 and $1760-1780 \mathrm{~cm}^{-1}$ ) were observed due to carbonyl stretch- ing. Stretching in $\mathrm{C}=\mathrm{C}$ chloroalkenes, ring vibration of benzene, $\mathrm{CH}_{2}$ deformation in $\mathrm{R}-\mathrm{CH}_{2}-\mathrm{CN}$ structure and $(\mathrm{C}=\mathrm{O})-\mathrm{O}-$ stretching in cypermethrin were reported by Kaur et al. (2015) using Fusarium sp. In the present study, FTIR spectra of biodegraded cypermethrin showed major changes in the range of $1000-1650$ and $2259-3431 \mathrm{~cm}^{-1}$, indicating degradation of cypermethrin. Similarly, Rosenheimer and Dubowski (2008) performed photolysis of thin films of cypermethrin using in situ FTIR monitoring. Identified photoproducts were 3-phenoxybenzaldehyde, 3phenoxybenzoic acid, acetonitrile and cypermethrin isomers (Rosenheimer et al. 2011).

\section{GC-MS analysis of cypermethrin metabolites}

Peaks of two compounds, GC1 (4.123 min) and GC2 (4.125 $\mathrm{min}$ ), appeared first during the cypermethrin biodegradation by SG2. These compounds were identified as phenol and 4-hydroxybenzoate, respectively, based on their retention time and molecular weight with those of corresponding authentic compounds in the database. Peaks of GC3 (8.348 $\mathrm{min})$ and GC4 $(8.587 \mathrm{~min})$ were observed and the corresponding compounds were 4-propylbenzaldehyde and phenol, M-tert-butyl as per the database. Similarly some other metabolites were also identified as they showed different retention time (Table 3). Based on the identity of the metabolites, biodegradation pathway of cypermethrin in strain SG2 was proposed and presented in Fig. 5. Cypermethrin was initially metabolized by the hydrolysis of ester linkage which yielded 3-(2, 2-dichloro ethenyl)-2,2-dimethyl-cyclopropanecarboxylate [GC15] and $\alpha$-hydroxy-3-phenoxybenzeneacetonitrile [GC7]. Compound GC7 was unstable in the environment and oxidized to form 3- phenoxybenzaldehyde [GC8]. Subse- 
DESIGN-EXPERT Plot
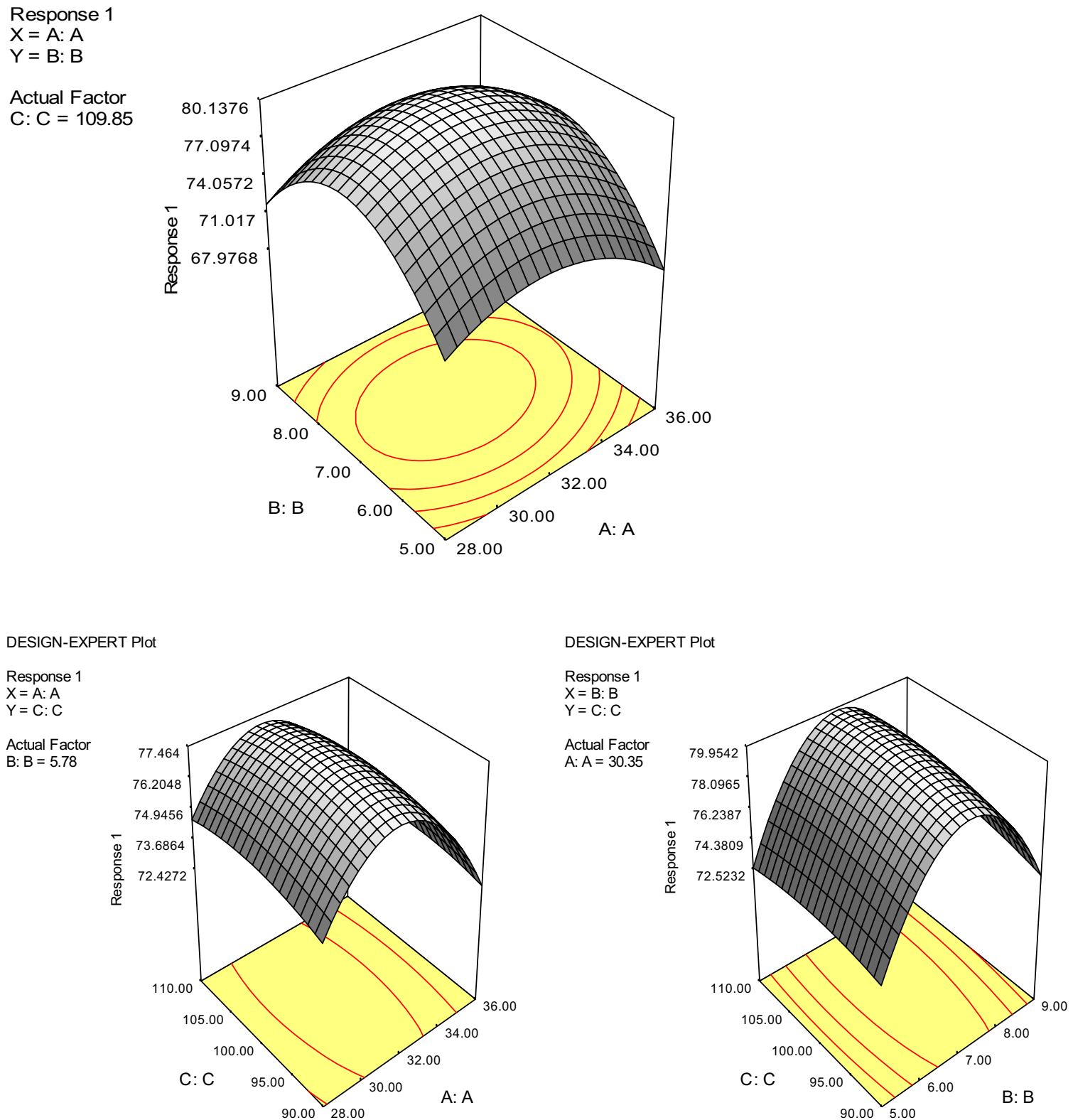

Fig. 3 Response surface plot showing effect of temperature, $\mathrm{pH}$ and shaking speed on cypermethrin biodegradation (where $A$ temperature, $B \mathrm{pH}$, $C$ shaking speed)

quent oxidation of GC8 resulted in the formation of 4-propylbenzaldehyde [GC3]. Compound GC3 could be further transformed to 4-hydroxybenzoate [GC2], which could be converted into phenyl ester of o-phenoxy benzoic acid (GC13). Subsequently, GC13 transformed into M-tertbutyl phenol (GC4), which can further be converted to 2-tert-pentylphenol (GC5). It is possible that GC1 and GC5 transformed into small molecular weight aliphatic compounds, i.e. 1-dodecanol (GC6), isopropyl myristate (GC9) and oleic acid (GC11) and may lead to complete mineralization of cypermethrin thereafter.

\section{Discussion}

Numerous studies have shown the isolation and characterization of pesticide degrading bacteria from pesticidecontaminated soil, groundwater and activated sludge (Tallur et al. 2008; Chen et al. 2011b; Negi et al. 2014). Bacillus sp. is widely existing in nature and safely used in a variety of food products because of its nontoxicogenic and non pathogenic properties, identified by Food and Drug Administration (Gong et al. 2014; Xiao et al. 2015). Bacillus sp. is also reported to degrade a number of 
Fig. 4 FT-IR spectra of cypermethrin. a Cypermethrin control. b Cpermethrin treated with SG2

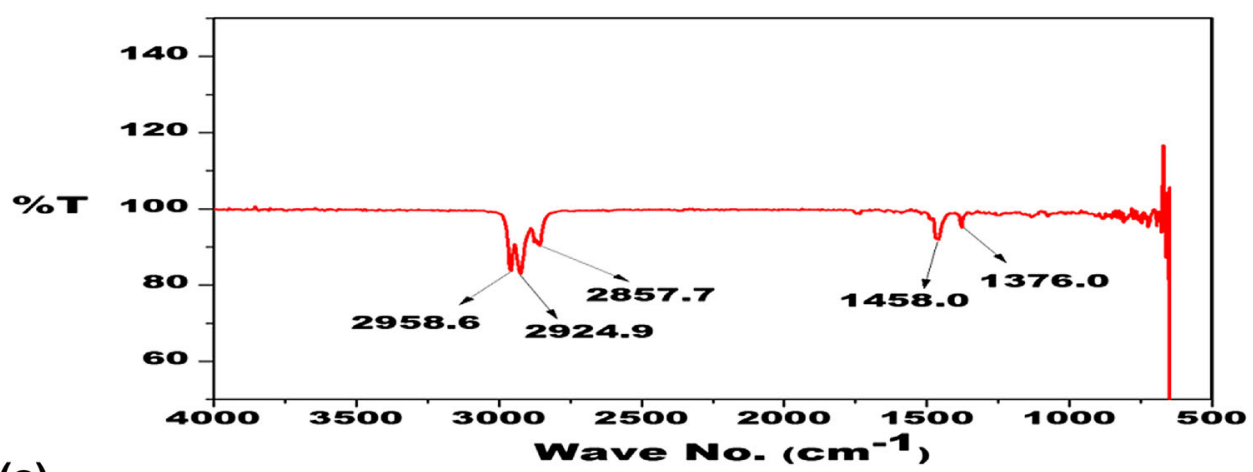

(a)

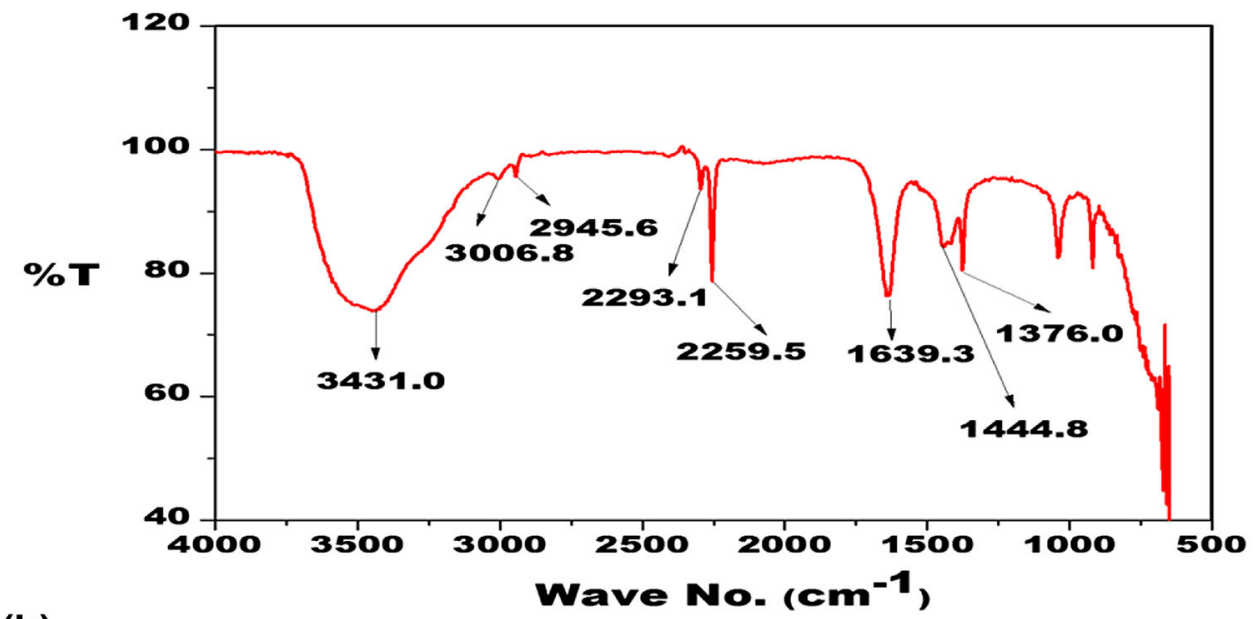

(b)

\begin{tabular}{lccl}
\hline $\begin{array}{l}\text { Intermediate metabolites } \\
\text { with their code number }\end{array}$ & $\begin{array}{l}\text { Retention time } \\
(\mathrm{min})\end{array}$ & $\begin{array}{l}\text { Molecular weight } \\
(\mathrm{MW})\end{array}$ & $\begin{array}{l}\text { Intermediate } \\
\text { metabolites }\end{array}$ \\
\hline GC1 & 4.123 & 94 & Phenol \\
GC2 & 4.125 & 138 & 4-Hydroxybenzoate \\
GC3 & 8.348 & 148 & 4-Propylbenzaldehyde \\
GC4 & 8.587 & 150 & Phenol, M-tert-butyl- \\
GC5 & 9.514 & 164 & 2-Tert-pentylphenol \\
GC6 & 10.908 & 186 & 1-Dodecanol \\
GC7 & 13.725 & 225 & a-Hydroxy-3- phenoxy- benzeneacetonitrile \\
GC8 & 13.728 & 198 & 3-Phenoxy-benzaldehyde, \\
GC9 & 14.906 & 270 & Isopropyl myristate \\
GC10 & 15.944 & 298 & Hexadecanoic acid, methyl ester \\
GC11 & 18.052 & 282 & Oleic Acid \\
GC12 & 18.917 & 270 & Isoamyl laurate \\
GC13 & 23.700 & 256 & Phenyl ester of o-phenoxy benzoic acid \\
GC14 & 23.958 & 415 & Cypermethrin \\
GC15 & 24.100 & 236 & 3-(2,2-dichloroethenyl)-2,2-dimethyl \\
& & & cyclopropanecarboxylate
\end{tabular}

Table 3 Identification of intermediate metabolites of cypermethrin by GC-MS xenobiotic compounds including 4-chloro-2 nitrophenol, red M5B dye, dimethylformamide and methyl parathion (Arora 2012; Gunasekar et al. 2013). Current study provides the evidence of efficient degradation pathway of cypermethrin by Bacillus sp. Strain SG2. The bacteria converted cypermetrin into smaller molecular weight 


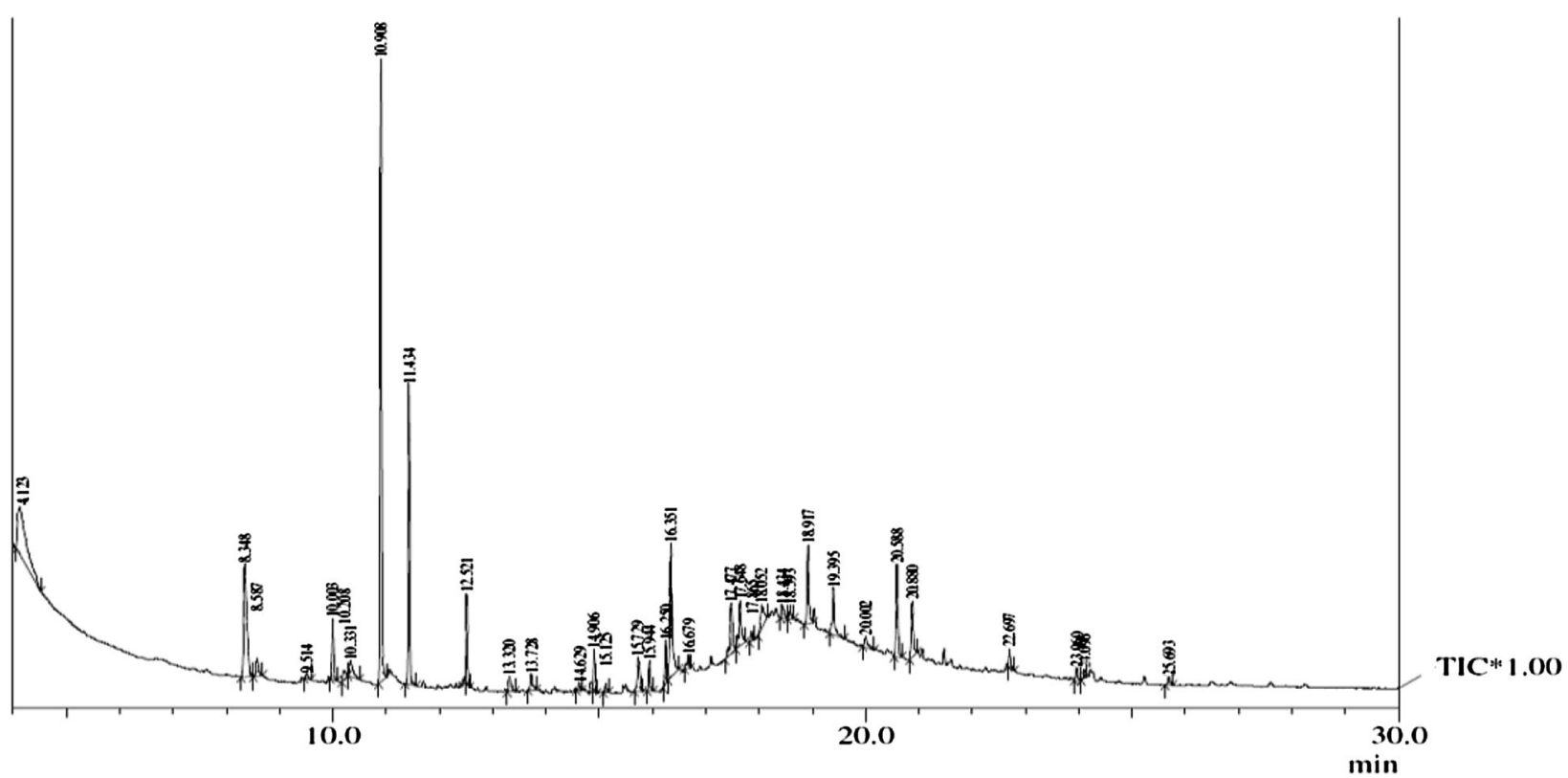

Fig. 5 GC-MS spectra of the cypermethrin with strain SG2

compounds which can further be mineralized under natural environmental conditions.

Biodegradation of cypermethrin increased with increased bacterial growth in minimal medium. Our observations are relevant with the findings of Singh et al. (2004) and Xiao et al. (2015). Strain SG2 could utilize cypermethrin as a sole carbon source and degraded it over a wide range of temperature $\left(28-38{ }^{\circ} \mathrm{C}\right), \mathrm{pH}(4-8)$ and shaking speed (90-110). The presence of longer exponential phase in the bacterial growth curve at initial higher cypermethrin concentration could be related to higher bacterial population requirement for pesticide degradation. It is proposed that higher initial bacterial counts were needed to initiate rapid degradation of the pesticide (Xiao et al. 2015). Bacillus sp. strain SG2 needed a longer lag phase to adapt to a new environment which induced the synthesis of degradative enzymes (Dubey and Fulekar 2013). The degradative enzymes do not show much substrate specificity, so one strain of Bacillus sp. can grow and degrade many hazardous substances. Strain SG2 could degrade all the pyrethroids because all the pyrethroid insecticides share a similar structure as reported by Wang et al. (2011).

The purpose to use RSM in the present study was to optimize the best culture conditions for maximum biodegradation of cypermethrin. RSM is the evaluation of relationships between the predicted values of the dependent variable and the conditions of dependent variables (Hosseini-Parvar et al. 2009). Box-Behnken design, as used commonly in industrial applications because of its economical design, requires only three levels of each factor.
Chen et al. (2011b) and Xiao et al. (2015) have used RSM, based on the Box-Behnken design to optimize the degradation condition of pyrethroid insecticides at different temperature, $\mathrm{pH}$ and inoculum size. They described that RSM is convenient and efficient system to investigate the optimum degradation conditions for pyrethroid insecticides by different microorganisms. In our study a statistical model based on RSM was applied to optimize the cypermethrin degradation conditions by strain SG2. The model was proved to be reliable and accurate within the limit of chosen factors.

As a strategy to develop efficient biodegradation conditions, it is important to analyse the metabolic pathway of the test compound. Most of the pyrethroid insecticides produce more toxic intermediates in biodegradation processes (Laffin et al. 2010). Our results showed that the strain SG2 was not only efficiently able to degrade cypermethrin but also transformed the metabolites (compound $\mathrm{GC} 1-\mathrm{GC} 15)$ into non toxic forms. Our results are in accordance to the reports of Zhang et al. (2011). It is presumed that ester hydrolysis of pyrethroid takes place by carboxylesterases. This enzyme acts as a regulatory enzyme for pyrethroid degradation and results in acid and alcohol production (Zhang et al. 2010; Xiao et al. 2015). Metabolites of biodegraded cypermethrin in soil slurry were extracted and identified by GC-MS (Table 3). Each peak was identified on the basis of its characteristic $\mathrm{m} / \mathrm{z}$ fragment ions and matched with authentic compounds available in the database. Chromatogram of GC-MS for cypermethrin degradation by strain SG2 is shown in Fig. 6. Cypermethrin disappeared concomitantly with the 
<smiles>CC1(C)C(CC(Cl)Cl)C1C(=O)OC(=O)[C@@H]1CCC=C(OC2CCCCC2)C1</smiles>

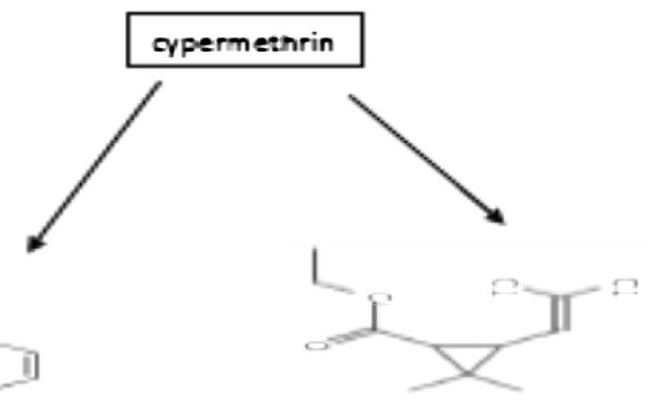

\section{a-Hydrosy-3-phenosy- Benzeneacetonitrile}

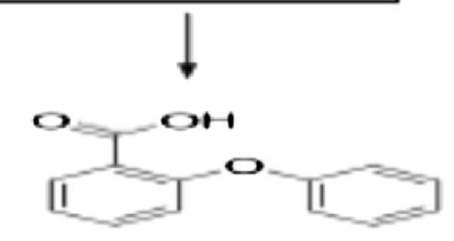

3-Phenoxy-Benzaldehyde

\section{Aliphatic hydrocarbon or Short chain compounds i.e 1-Dodecanol Isopropyl Myristate. Oleic Acid. Isoamyl Laurate etc.}

\section{3-(2.2-Dichlaroetheny )-2.2-}

dimethyl cyclopropanecarboxylate

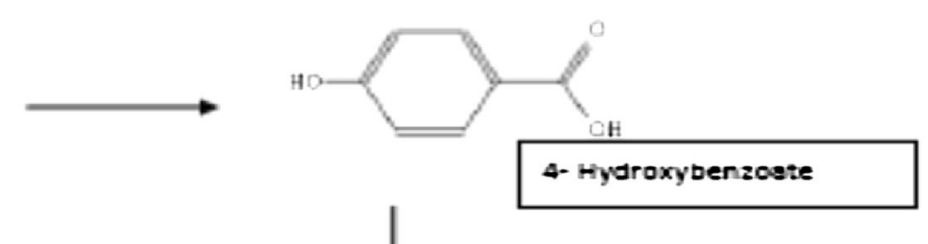

4-Propyl Beenolideityde

Phreyil otere of o-Phrooxy bensoic acid

$\downarrow$

Phenol, M-Tert-Buty<smiles>ClC1CCC2CCC1C2</smiles><smiles>C1CCCC1</smiles><smiles>CC1CCCCC1C</smiles>

Phenol

Fig. 6 Proposed pathway of Cypermethrin degradation with SG2 strain

formation of new metabolites. In the present study, cypermethrin was metabolized to several intermediate compounds which were further transformed into non- toxic and environmentally accepted forms. By arranging the metabolites into their location in the pathway we have proposed the hypothetical degradation pathway of cypermethrin using strain SG2. Maximum degradation of cypermethrin was observed in soil slurry; hence intermediate compounds of biodegraded cypermethrin were extracted from soil slurry after 15 days. Cypermethrin could be metabolised into two major compounds ( $\alpha$-hydroxy-3-phenoxy- benzene acetonitrile and 3-(2, 2-dichloroethenyl)-2,2-dimethyl cyclopropanecarboxylate). $\alpha$-hydroxy-3- phenoxy- benzene acetonitrile is unstable and spontaneously transformed to yield 3-phenoxy benzaldehyde (Chen et al. 2011b; Lin et al. 2011; Xiao et al. 2015). 3- phenoxybenzaldehyde has antimicrobial activity, but does not affect producing culture and enhances biodegradation in soil or media (Chen et al. 2011b). 3phenoxybenzaldehyde is transformed into 
4-propylbenzaldehyde which again converts to 4-hydroxybenzoate. Afterward 4-hydroxybenzoate was metabolized by strain SG2 to form phenyl ester of o-phenoxy benzoic acid. Two intermediate metabolites (3-phenoxybenzoic acid and 3-phenoxybenzaldehyde) are the key metabolites of pyrethroids (Laffin et al. 2010). Chen et al. (2011c) reported the degradation of 3-phenoxybenzoic acid by Stenotrophomonas sp. strain ZS-S-01. A Pseudomonas sp. was also able to utilise $\beta$-cypermethrin (Halden et al. 1999). In the present study, metabolites of 3-phenoxybenzaldehyde degradation were also reported. Strain SG2 was also able to use 3-phenoxybenzaldehyde. These results demonstrate that Bacillus sp. strain SG2 possesses the metabolic pathway for the complete detoxification of cypermethrin, indicating that strain SG2 may be an ideal microorganism for bioremediation of the cypermethrin in contaminated soil or water system.

Acknowledgments Financial support by Ministry of Environment and Forestry, New Delhi, India, is duly acknowledged.

\section{Compliance with ethical standards}

Conflict of interest Author declares no conflict of interest.

Open Access This article is distributed under the terms of the Creative Commons Attribution 4.0 International License (http:// creativecommons.org/licenses/by/4.0/), which permits unrestricted use, distribution, and reproduction in any medium, provided you give appropriate credit to the original author(s) and the source, provide a link to the Creative Commons license, and indicate if changes were made.

\section{References}

Anastassiades M, Lehotay SJ, Stajnbaher D, Schenck FJ (2003) Fast and easy multi residue method employing extraction/partitioning and dispersive solid phase extraction for the determination of pesticide residues in produce. J AOAC Int 86:412-431

Arora PK (2012) Decolourization of 4-chloro-2-nitrophenol by a soil bacterium, Bacillus subtilis RKJ 700. PLoS One 7:e52012

Bazzicalupo M, Fani R (1995) The use of RAPD for generating specific DNA probes for microorganisms. In: Clap JP (ed) Methods in molecular biology. Species diagnostic protocols: PCR and other nucleic acid methods. Humana Press Inc, Totowa, pp $155-175$

Chen SH, Lai KP, Li YN, Hu MY, Zhang YB, Zeng Y (2011a) Biodegradation of deltamethrin and its hydrolysis product 3-phenoxybenzaldehyde by a newly isolated Streptomyces aureus strain HP-S-01. Appl Microbiol Biotechnol 90:1471-1483

Chen SH, Yang L, Hu MY, Liu JJ (2011b) Biodegradation of fenvalerate and 3-phenoxybenzoic acid by a novel Stenotrophomonas sp. strain ZS-S-01 and its use in bioremediation of contaminated soils. Appl Microbiol Biotechnol 90:755-767

Chen SH, Hu MY, Liu JJ, Zhong GH, Yang L, Rizwan-ul-Haq M, Han HT (2011c) Biodegradation of betacypermethrin and 3phenoxybenzoic acid by a novel Ochrobactrum lupini DG-S-01. J Hazard Mater 187:433-440

Cycoń M, Zmijowska A, Piotrowska-Seget Z (2014a) Enhancement of delta methrin degradation by soil bioaugmentation with two different strains of Serratia marcescens. Int $\mathrm{J}$ Environ Sci Technol 11:1305-1316

Cycoń M, Zmijowska A, Piotrowska-Seget Z (2014b) Enhancement of delta methrin degradation by soil bioaugmentation with two different strains of Serratia marcescens. Int J Environ Sci Technol 11:1305-1316

Dubey KK, Fulekar MH (2013) Investigation of potential rhizospheric isolate for cypermethrin degradation. Biotech 3:33-43

Fan X, Liu X, Huang R, Liu Y (2012) Identification and characterization of a novel thermostable pyrethroid-hydrolyzing enzyme isolated through metagenomic approach. Microb Cell Fact 11:33

GongQW Zhang C, Lu FX, Zhao HZ, Bie XM, Lu ZX (2014) Identification of bacillomycin D from Bacillus subtilis fmbJ and its inhibition effects against Aspergillus flavus. Food Control 36:8-14

Gunasekar V, Gowdhaman D, Ponnusami V (2013) Biodegradation of reactive red M5B dye using Bacillus subtilis. Biodegradation 5:131-135

Halden RU, Tepp SM, Halden BG, Dwyer DF (1999) Degradation of 3- phenoxybenzoic acid in soil by Pseudomonas pseudoalcaligenes POB310 (pPOB) and two modified Pseudomonas strains. Appl Environ Microbiol 65:3354-3359

Holt JG, Krieg NR, Sneath PH, Staley JT, Williams ST (1994) Bergey's manual of determinative bacteriology, 9th edn. Willian and Wilkins, Baltimore

Hosseini-Parvar SH, Keramat J, Kadivar M, Khanipour E, Motamedzadegan A (2009) Optimising conditions for enzymatic extraction of edible gelatin from the cattle bones using response surface methodology. Int J Food Sci Technol 44:467-475

Kaur P, Sharma A, Parihar L (2015) In vitro study of mycoremediation of cypermethrin-contaminated soils in different regions of Punjab. Ann Micobiol. doi:10.1007/s13213-015-1033-1

Khanna RN, Gupta GSD, Anand M (2002) Kinetics of distribution of cypermethrin in blood, brain, and spinal cord after a single administration to rabbits. Bull Environ Contam Toxicol 69:749-755

Laffin B, Chavez M, Pine M (2010) The pyrethroid metabolites 3phenoxybenzoic acid and 3-phenoxybenzyl alcohol do not exhibit estrogenic activity in theMCF-7 human breast carcinoma cell line or Sprague-Dawley rats. Toxicology 267:39-44

Li QY, Li Y, Zhu XK, Cai BL (2008) Isolation and characterization of atrazine-degrading Arthrobacter sp. AD26 and use of this strain in bioremediation of contaminated soil. $\mathrm{J}$ Environ Sci 20(10): 1226-1230

Lin QS, Chen SH, Hu MY, Rizwan-ul-Haq M, Yang L, Li H (2011) Biodegradation of cypermethrin by a newly isolated actinomycetes HU-S-01 from wastewater sludge. Int $\mathrm{J}$ Environ Sci Technol 8:45-56

Narahashi T, Ginsburg KS, Nagata K, Song JH, Tatebayashi H (1998) Ion channels as targets for insecticides. Neurotoxicology 19:581-590

Negi G, Pankaj Srivastava A, Sharma A (2014) In situ biodegradation of endosulfan, imidacloprid, and carbendazim using indigenous bacterial cultures of agriculture fields of Uttarakhand, India. Int J Biol Food Vat Agric Eng 8(9):935-943

Patel S, Pandey AK, Bajpayee M, Parmar D, Dhawan A (2006) Cypermethrininduced DNA damage in organs and tissues of the mouse: evidence from the comet assay. Mutat Res 607:176-183

Rosenheimer MS, Dubowski Y (2008) Photolysis of thin films of cypermethrin using in situ FTIR monitoring: products, rates and quantum yields. J Photochem Photobiol 200:262-269

Rosenheimer MS, Linker R, Dubowski K (2011) Heterogeneous oxidation of the insecticide cypermethrin as thin film and airborne particles by hydroxyl radicals and ozone. Phys Chem Chem Phys 13:506-517 
Saxena P, Saxena AK (2010) Cypermethrin induced biochemical alterations in the blood of albino rats. Jordan $\mathrm{J}$ Biol Sci 3:111-114

Shafer TJ, Meyer DA, Crofton KM (2005) Developmental neurotoxicity of pyrethroid insecticides: critical review and future research needs. Environ Health Perspect 113:123-136

Singh BK, Walker A, Morgan JA, Wright DJ (2004) Biodegradation of chlorpyrifos by Enterobacter strain B-14 and its use in bioremediation of contaminated soils. Appl Environ Microbiol 70:4855-4863

Soderlund DM, Clark JM, Sheets LP, Mullin LS, Piccirillo VJ, Sargent D, Stevens JT, Weiner ML (2002) Mechanisms of pyrethroid neurotoxicity: implications for cumulative risk assessment. Toxicology 171:3-59

Tallur PN, Megadi VB, Ninnekar HZ (2008) Biodegradation of cypermethrin by Micrococcus sp. strain CPN 1. Biodegradation 19:77-82

Tamura K, Dudley J, Nei M (2007) MEGA4: molecular evolutionary genetics analysis (MEGA) software version 4.0. Mol Biol Evol 24:1596-1599

Wang BZ, Ma Y, Zhou WY, Zheng JW, He J (2011) Biodegradation of synthetic pyrethroids by Ochrobactrum tritici strain pyd-1. World J Microbiol Biotechnol 27:2315-2324
Xiao Y, Chen S, Gao Y, Hu W, Hu M, Zhong G (2015) Isolation of a novel beta-cypermethrin degrading strain Bacillus subtilis BSF01 and its biodegradation pathway. Appl Microbiol Biotechnol 99:2849-2859

Xu L, Liu L, Ren X, Zhang M, Cong N, Xu A, Shao J (2008) Evaluation of androgen receptor transcriptional activities of some pesticides in vitro. Toxicology 243:59-65

Zhai Y, Li K, Song JL, Shi YH (2012) Molecular cloning, purification and biochemical characterization of a novel pyrethroid-hydrolyzing carboxylesterase gene from Ochrobactrum anthropi YZ-1. J Hazard Mater 221-222:206-212

Zhang C, Jia L, Wang SH, Qu J, Xu LL, Shi HH, Yan YC (2010) Biodegradation of beta-cypermethrin by two Serratia spp. with different cell surface hydrophobicity. Bioresource Technol 101:3423-3429

Zhang C, Wang SH, Yan YC (2011) Isomerization and biodegradation of beta-cypermethrin by Pseudomonas aeruginosa $\mathrm{CH} 7$ with biosurfactant production. Bioresource Technol 102:7139-7146 